\title{
Electrical Cardioversion in Pregnancy: How Do We Do?
}

\author{
Gebelikte Elektriksel Kardiyoversiyon: Nasıl Yapalım?
}

\author{
Süleyman Ercan', Vedat Davutoğlu', İbrahim Sarı', Suat Zengin², Hasan Büyükaslan³ \\ 'Department of Cardiology, Faculty of Medicine, Gaziantep University, Gaziantep, Turkey \\ 2Department of Emergency Medicine, Faculty of Medicine, Gaziantep University, Gaziantep, Turkey \\ ${ }^{3}$ Department of Emergency Medicine, ŞanllurfaTraining and Research Hospital, Şanllurfa, Turkey
}

\section{ABSTRACT}

Introduction: Complaints of palpitations during pregnancy are common and often follow a benign clinical course. Tachycardia requiring intervention occurs in about $0.2-0.3 \%$ of these patients.

Case Report: A pregnant 27-year-old with a history of rheumatic mitral valve disease was admitted with complaints of palpitations. Patient developed new onset atrial fibrillation and, with the implemented successful direct current electrical cardioversion, returned to sinus rhythm.

Conclusion: Electrical cardioversion, applied with attention to placement with low-joule and foetuses kept as far as possible away from the pad, is considered to be safe in pregnant women with arrhythmia requiring cardioversion.

Keywords: Pregnancy, atrial fibrillation, electrical cardioversion

Received: 24.04.2012 Accepted:01.01.2013

\section{ÖZET}

Giriş: Gebelikte çarpıntı şikayeti sık görülür ve çoğu selim seyirlidir. Bu hastaların \%0.2-0.3 kadarında müdahaleyi gerektiren taşikardi görülür.

Olgu Sunumu: Romatizmal mitral kapak hastalığı öyküsü olan 27 yaşındaki bir gebe çarpıntı şikayeti ile başvurdu. Yeni başlangıçlı atriyal fibrilasyon tespit edilen hastaya başarılı dogru akım elektriksel kardiyoversiyon uyguladı ve ritmi sinüse döndü.

Sonuç: Kardiyoversiyon gerektiren aritmisi olan gebelerde, en düşük joule ve olabildiğince fetustan uzak ped yerleşimine dikkat edilerek uygulanacak elektriksel kardiyoversiyon, güvenli olarak kabul edilmektedir.

Anahtar Kelimeler: Gebelik, atriyal fibrilasyon, elektriksel kardiyoversiyon

Geliş Tarihi: 24.04.2012 Kabul Tarihi: 01.01.2013

\section{Giriş}

Gebelikte çarpıntı sık karşılaşılan semptomlardan biridir ve bu şikayeti olanların \%60'ında çeşitli aritmilere rastlanmaktadır. Bu aritmilerin çoğu selim seyirli sinüsal taşikardi veya ektopik vurulardan oluşmaktadır. Bu hastaların ancak \%0,2-0,3 kadarında müdahaleyi gerektiren taşikardi görülür (1). Taşikardilerin büyük kısmını ise supraventriküler aritmiler oluşturmaktadır. Konjenital kalp hastalı̆ı ve özellikle bölgemizde sık görülmekte olan romatizmal kapak hastalı̆ının varlığı (2), supraventriküler aritmilerden atriyal fibrilasyonun (AF) gelişim riskini artıırmaktadır. Romatizmal mitral kapak hastalığı öyküsü olan bir gebede gelişen yeni başlangıçlı AF'nin doğru akım (DC) kardiyoversiyonla ritminin sinüse döndürülmesi olgusunu paylaşarak, bu yazımızla gebelikte AF gelişen vakalara yaklaşımı gözden geçirmeyi amaçıyoruz.

\section{Olgu Sunumu}

Romatizmal kapak hastalığı öyküsü olan 26 yaşındaki 27 haftalık gebe, 3 gündür olan çarpıntı şikayeti ile kliniğimize başvurdu. Elektrokardiyografisinde hızlı ventrikül cevaplı AF mevcuttu (Resim 1). Transtorasik ekokardiyografide, orta derecede romatizmal mitral yetmezlik, hafif mitral darlık, hafif triküspit yetmezliği izlendi ve tahmini sistolik pulmoner arter basıncı 40 mmHg olarak hesaplandı. Hastaya kardiyoversiyon planlandı, bu nedenle transözafagiyal ekokardiyografi (TEE) yapılarak sol atriyal apendikste trombüs varlığı dışlandı. Kısa etkili benzodiyazepinle sedasyon yapılarak, bifazik defibrilatör ile $100 \mathrm{~J}$ enerji ile antero-lateral 
pozisyonda DC kardiyoversiyon yapıldı. İlk şoktan verme işleminden sonra hastanın ritmi sinüse döndü (Resim 2). Hastanın vital bulguları stabil seyretti. Fetal distres kontrolü için yapılan elektronik kardiyotokografide normal patern izlendi (Resim 3). Hastadan onam formu alındı.

\section{Tartışma}

Yeni başlayan AF, özellikle darlığın komponentinin eşlik ettiği kalp kapak hastalarında tolere edilememektedir. Sıklıkla acil servise yeni başlayan çarpıntı ve nefes darlığı ile başvurabildikleri gibi, bazen hemodinamik kollaps ve kardiyojenik şok tablosunda gelebilirler. Gelişen aritmi hemodinamik instabilite ile uteroplasental perfüzyonu bozarak ve/veya fetüste aritmileri tetikleyerek fetüsün sağlığını olumsuz etkileyebilir (3). Bu hastalarda öncelikli tedavi seçeneği kardiyoversiyondur. Her ne kadar AF başlangıcından sonraki ilk 48 saat içerisinde tromboemboli riskinin düşük olduğu kabul edilip doğrudan kardiyoversiyon yapılabileceği önerilse de (4) gebelikte artmış tromboemboli riski nedeniyle bu hastalarda kardiyoversiyon öncesi rutin olarak, sol atriyal apendiks trombüs varlığının ekarte edilmesi uygun olacaktır (5). Bizim olgumuzda da yapılan TEE'de atriyal apendikste trombüs varlığı dışlandıktan sonra kardiyoversiyon planlandı.
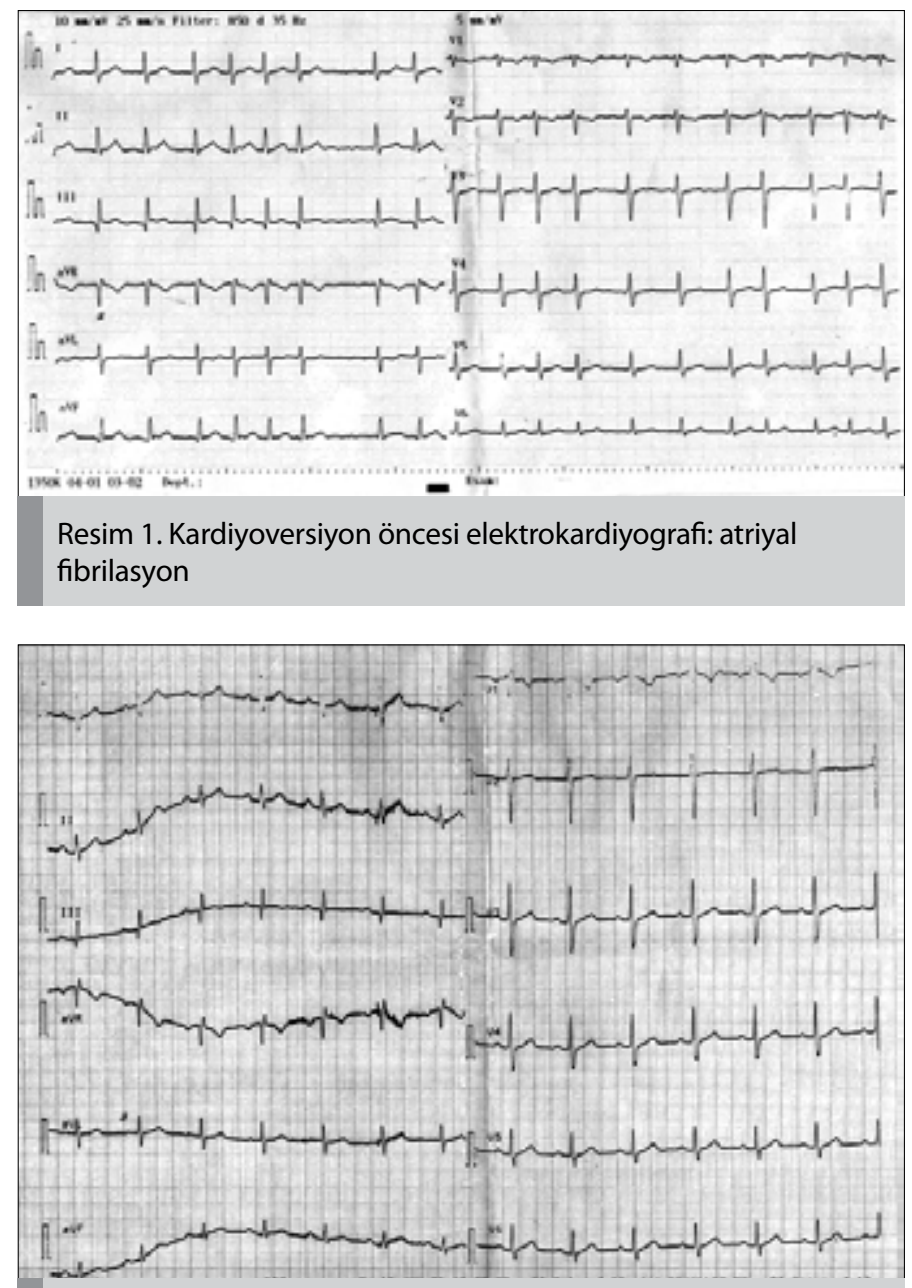

Resim 2. Kardiyoversiyon sonrası elektrokardiyografi: sinüs ritmi
B-blokerler, flekainid, prokainamid gebelerdeki net güvenlik bilinmemekle beraber klinik uygulamalar gözlemi neticesinde göreceli güvenlikte kabul edilen antiaritmik ajanlardır (3). Amiodoron özellikle yenidoğan hipotirodi gibi ciddi fetal yan etkilere neden olabildiğinden, ön planda düşünülmemelidir.

Supraventriküler taşikardik veya AF hastası hemodinamik olarak stabil değilse ve kardiyojenik şok tablosu mevcutsa DC kardiyoversiyon derhal uygulanmalıdır. Hemodinamik olarak stabil durumdaysa TEE ile sol atriyal trombüs varlığı ekarte edildikten sonra, medikal kardiyoversiyon denenebilir. Vaka çalışmaları gebeliğin her evresinde DC kardiyoversiyonun anne ve fetüs sağlığı açısından güvenle kullanılabileceğini göstermektedir. Ayrıca DC kardiyoversiyonda fetüse ulaşan akım miktarının düşük olduğuna inanılmaktadır (3). Bizim vakada olduğu gibi gebelikte güvenli olması ve hızlı etkisi nedeniyle hemodinamik olarak stabil hastalarda da DC kardiyoversiyonu bir seçenek olarak düşünebiliriz. Nitekim kardiyoversiyon sonrasında hastanın vital bulguları stabil seyretti ve komplikasyon gelişmedi. Ayrıca embriyogenesiz sürecinde gebeliğe sahip hastalara, ilaçların olası teratojenik riski nedeniyle de medikal kardiyoversiyon yerine DC kardiyoversiyon öncelikle düşünülmelidir.

Kardiyoversiyon planlanan hastalarda, fetüs işlem öncesi ve esnasında dikkatli biçimde monitörize edilmelidir. Bazı uzmanlar, mide içeriğinin aspirasyonu riski nedeniyle genel anestezi ve entübasyon ile işlemin yapılmasını önerse de en az 6 saat açlık sonrası yapılan sedasyonla da işlem gerçekleştirilebilir. DC kardiyoversiyonda verilen enerji miktarı gebe olmayanlardakilerde olduğu gibi ayarlanmalıdır (4). Vaka çalışmalarında AF'de 50-400 joule enerji kullanılmıştır. Kardiyoversiyon için pedlerin yerleşimi için özel bir lokalizasyon şekli belirtilmemiş olsa da amniyon sıvısı iyi geçirgen özelliğe sahip olduğundan, kullanılacak pedlerin fetüsten olabildiğince uzağa yerleştirilmesine dikkat edilmelidir. Bizim olguda ise kısa etkili benzodiyazepinle sedasyon yapıldı, bifazik defibrilatör ile $100 \mathrm{~J}$ enerji ile antero-lateral pozisyonda başarılı DC kardiyoversiyon yapıldı.

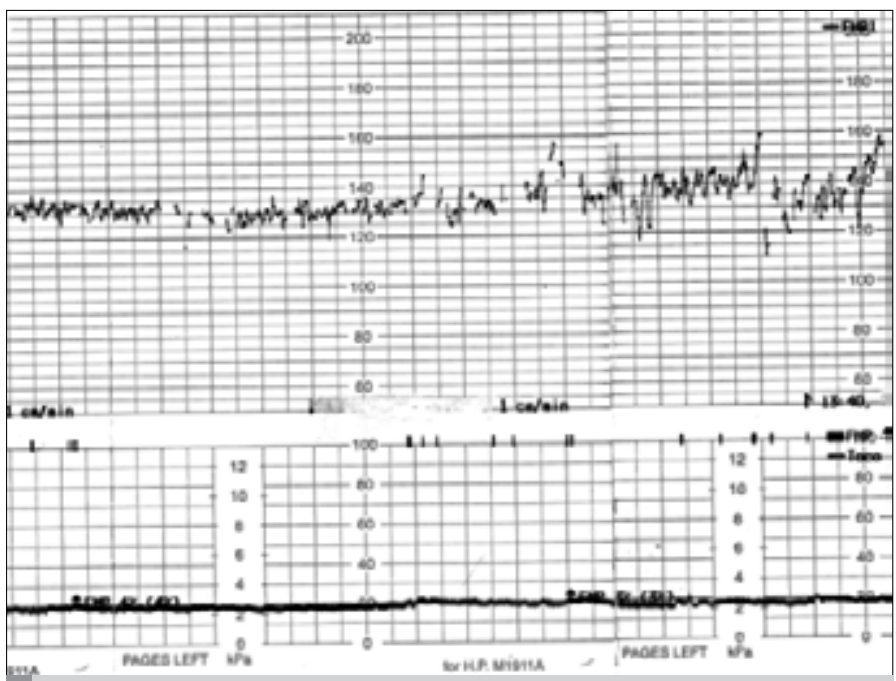

Resim 3. Elektronik fetal kardiyotokografide normal patern 
Gebelikte DC kardiyoversiyonun uygulandığı 44 vakanın derlemesinde bir veya daha fazla şoklama ile sinüs ritminin sağlanması 41 hastada gerçekleşmiştir ki bu sonuç gebe olmayanlarda yapılan DC kardiyoversiyon sonuçlarına benzerdir. Gebelerde uygulanan DC kardiyoversiyonla doğrudan ilişkili ölüm vakası bildirilmemiştir. Ancak nadir de olsa uterus kontraksiyonlarını tetikleyerek veya fetal strese yol açarak erken doğuma neden olabileceği akılda tutulmalıdır (6). Hastamızda yapılan elektronik kardiyotokografide fetal distrasin olmadığı görüldü.

\section{Sonuç}

Gebelikte çarpıntı sık şikayetlerdendir. Kardiyoversiyon gerektiren aritmi olguları özellikle kardiyak öyküsü olanlara eşlik etmektedir. Bu hastalarda erken dönemde kardiyoversiyon embolik komplikasyonların önlenmesi açısından önemlidir. Düşük joule ve olabildiğince fetustan uzak ped yerleşimine dikkat edilerek gebelerde uygulanacak DC kardiyoversiyon güvenli olarak kabul edilmektedir.

Conflict of Interest: No conflict of interest was declared by the authors.

Peer-review: Externally peer-reviewed.

Informed Consent: Written informed consent was obtained from patients who participated in this case.

Author Contributions: Concept - S.E.; Design - I.S.; Supervision - S.Z., V.D.; Funding - S.E.; Data Collection and/or Processing - S.Z.; Analysis and/or Interpretation - S.E., V.D.; Literature Review - H.B.; Writer - S.E.; Critical Review - I.S., S.Z.

Financial Disclosure: The authors declared that this study has received no financial support.
Çıkar Çatışması: Yazarlar çıkar çatışması bildirmemişlerdir.

\section{Hakem değerlendirmesi: Dış bağımsız.}

Hasta Onamı: Yazılı hasta onamı bu olguya katılan hastalardan alınmıştır.

Yazar Katkıları: Fikir - S.E.; Tasarım - I.S.; Denetleme - S.Z., V.D.; Kaynaklar - S.E.; Veri toplanması ve/veya işlemesi - S.Z.; Analiz ve/veya yorum - S.E., V.D.; Literatür taraması - H.B.; Yazıyı yazan - S.E.; Eleştirel Inceleme - I.S., S.Z.

Finansal Destek: Yazarlar bu çalışma için finansal destek almadıklarını beyan etmişlerdir.

\section{Kaynaklar}

1. Adamson DL, Nelson-Piercy C. Managing palpitations and arrhythmias during pregnancy. Heart 2007; 93: 1630-6.

2. Ozer O, Davutoglu V, Sari I, Akkoyun DC, Sucu M. The spectrum of rheumatic heart disease in the southeastern Anatolia endemic region: results from 1900 patients. J Heart Valve Dis 2009; 18: 68-72.

3. Atar I, Özin B. Gebelik sırasında gelişen atriyal fibrilasyon atağına yaklaşım. TAPE 2004; 2: 61-4.

4. European Heart Rhythm Association; European Association for CardioThoracic Surgery, Camm AJ, Kirchhof P, Lip GY, Schotten U, et al. Guidelines for the management of atrial fibrillation: the Task Force for the Management of Atrial Fibrillation of the European Society of Cardiology (ESC). Eur Heart J 2010; 31: 2369-429.

5. Alıcı MH, Soydinç HE, Ercan S, Davutoğlu V. Sinüs ritmindeki mitral darlıklı gebe bir kadında sol atriyal trombüs ve ilişik literatür taraması. MN Kardiyoloji 2012; 2: 85-7.

6. Tromp CH, Nanne AC, Pernet PJ, Tukkie R, Bolte AC. Electrical cardioversion during pregnancy: Safe or not? Neth Heart J 2011; 19: 134-6. 